\title{
Assessment of Nitrate and Heavy Metal Pollution of Groundwaters in the Intensive Agricultural Areas
}

\author{
Bülent Topcuoğlu \\ Akdeniz University, Vocational School of Technical Sciences, Antalya Turkey.
}

\begin{abstract}
A survey study was conducted in groundwaters and soils of intensive agricultural areas of Antalya, one of the major greenhouse production region of Turkey to assess the nitrate and heavy metal pollution and their relationships with soil metal parameters.Land altitude of greenhouse regions are varied in a wide range and groundwater table is changed depending on the regions. Physico-chemical characteristics of groundwaters in the majority of greenhouse areas were within the acceptable limit values and differences in characteristics among the regions were found statistically important. Groundwaters have low electrical conductivity, slightly alkaline reaction, low and moderate alkalinity. Dissolved oxygen (DO), biological oxygen demand (BOD), chemical oxygen demand (COD) and total dissolved solids (TDS) were detected in acceptable ranges. Total NO3- values of groundwaters were generally excessed permissible safe limits for drinking waters. Nitrate pollution evaluation values of groundwaters are indicated that due to higher NO3-contents of groundwaters there are a possible health risks for the consumptions of groundwaters as drinking water in a moderate and longterm in the greenhouse regions.

Total As and Fe contents of almost all ground waters were above the permissible pollution limits. All other heavy metal concentrations of groundwaters were below the limits. According to evaluation parameters, generally, it can be concluded that all ground waters in regional size may be considered less contaminated, and in point of heavy metals and pollutants is in acceptable limits. Groundwater nitrate and Ni concentrations were positively correlated with soil nitrate and Ni concentrations. Most of groundwater metals were positively correlated soil $\mathrm{F} 1$ and $\mathrm{F} 2$ metal fractions and $\mathrm{Zn}, \mathrm{Mn}, \mathrm{Cu}$ and As in groundwaters were positively correlated with soil metal mobility factor.
\end{abstract}

Keywords: Groundwaters, Greenhouse Soil, Nitrate, Heavy Metals

\section{Introduction}

Due to intensive use of agrochemicals in greenhouse soils, nitrate nitrogen and heavy metals is become to common pollutant in ground waters of greenhouse soils and adjacent environment. Especially, high concentration of nitrate nitrogen in groundwaters is accepted as an important indicator of agricultural pollution.

Nitrate pollution in intensive greenhouse areas is an important environmental problem that threats sustainable production and national economy and interests particularly for public health. Nitrate poses health risk to humans. It can cause 'blue baby syndrome' or methaemoglobinemia among infant. Nitrate also can cause gastrointestinal illness, multiple digestive tract impairment, indigestion and imflammation of the stomach, gastroenteritis, abdominal pain, dierrhea and blood in the urine and faeces. In addition, low level exposure to nitrate over many years, possibly could cause certain types of cancer such as digestive system cancer, stomach, esophagus, lungs, colon, bladder, ovaries, testicles, urogenital tract and non-hodgkins lymphoma [1].

Repeated amendments of organic matter and intensive use of fertilizers, and other agrochemicals may cause soil, ground water and environmental pollution in greenhouses. Although greenhouse areas a have great impact on environment due to intensive use of agrochemicals, little attention has been paid to nitrate and metal 
accumulation of groundwaters around greenhouses and environmental pollution assessment in ground waters with respect to comprehensive and integrated environmental evaluation.

The impact of agricultural activity on water sources has been widely acknowledged and its impact on surface water of nitrogen) and anthropogenic sources (i.e., industrial residue, intensive agriculture and septic tanks). Among them, heavy used of nitrogenous fertilizers in agricultural activities were the largest contribution of systems has been described in numerous studies [2]. Especially, the relationship between agricultural practices and the dissolution of nitrate in groundwater, as well as other pollutants have been studied in a number of case studies [3]. Nitrate in ground water accumulating from both natural (i.e., soil mineralization and atmospheric deposition nitrate in ground water [4].

Mediterranean region has an important agricultural potential especially greenhouse cultivation with its special climate and geographical characteristics in Turkey. Greenhouse cultivation has resulted in increasing usage of nitrogenous fertilizers and in recent years, many research findings have indicated that an extreme fertilizer and pesticide applications in the greenhouse soils of Mediterranean region. Crop plants which are cultivated in contaminated soils can accumulate contaminants and transfer them to animals and human beings via food chain which are eventually result in various health problems. Additionally, nitrate was more affects the ground water rather than phosphates in which related to agricultural activities and animal farming [5].

Assessment of extent of pollution in ground waters come into prominence with regard to prevention of possible risks. The aim of this study was to provide information on the nitrate and heavy metal levels in ground water and to assess the groundwater pollution by using soil parameters in the greenhouse regions.

\section{Material And Methods}

\subsection{Geography of Study Region}

The experiment was conducted on the major greenhouse vegetable growing area located at Antalya, Turkey. The site studied is intensively cultivated and is not industrialized area. The experiment was carried out at greenhouse region and water samples were taken from 10 sub-region and 162 sampling points (Fig. 1).

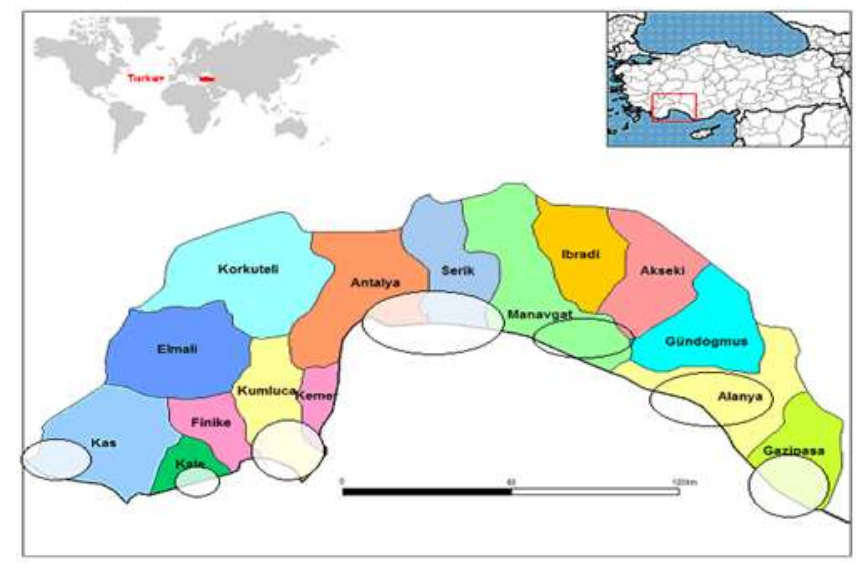

Fig. 1: Map of greenhouse regions in Antalya, Turkey

The geological materials of greenhouse area are mainly of calcareous nature and nearby to Mediterranean sea with average $57,8 \mathrm{~m}$ altitude. The land is influenced by a Mediterranean climate with a high average annual rainfall $\left(1081,5 \mathrm{~mm} /\right.$ year), the annual average temperature being around $18,7{ }^{\circ} \mathrm{C}, 63,8 \%$ average humidity and average 164 sunny days per year. As for greenhouses, the annual temperature is higher inside than outside, and most of them are watered by sprinklers with ground water source at the same point. All greenhouses have passive ventilation to control temperature and humidity inside. A great number of greenhouse soils is artificially built up with a different layer of sand, organic matter and other soil source. 


\subsection{Groundwater Sampling and Analysis}

Water samples taken for metal analysis were collected in polyethylene (HDPE) bottles (washed with detergent then with double-distilled water followed by $2 \mathrm{M}$ nitric acid, then double-distilled water again and finally with sampled water). Water samples were acidified with $10 \%$ HNO3 for metal analysis, samples were stored in an ice-box and brought to the laboratory and kept refrigerated and analyzed immediately within $24 \mathrm{~h}$.

Water samples taken for nitrate and other physiochemical analysis were collected in polyethylene bottles of 1 liter. Before sampling, the recipient was cleaned several times using the pumped water. Water samples were gradually filled to avoid turbulences and aeration during the sampling. To avoid sampling artifacts and analytical artifacts, in particular the gain of dissolved gas and microbiological activity, water samples were immediately cooled at $4{ }^{\circ} \mathrm{C}$ using portable icebox. Analysis was further performed as fast as possible and this within $24 \mathrm{~h}$ after sampling.

Groundwater samples were analyzed for nitrate as NO3-N by the Cadmium Reduction Flow Injection Method, [6]. Other routine analysis in water samples were analysed according to Standard methods recommended by APHA [7]. $\mathrm{pH}$ was measured by digital $\mathrm{pH}$ meter, electrical conductivity was measured by conductometry. Alkalinity was determined by titration with $0.01 \mathrm{~N} \mathrm{H2SO}$, Total dissolved solids (TDS) was measured by TDS meter. Dissolved oxygen (DO), biological oxygen demand (BOD) was measured by Wrinkler's method and chemical oxygen demand (COD) by Reflux method [7]. pH, electrical conductivity (EC), DO and nitrate were measured on site.

To determine heavy metals in water samples, $10 \mathrm{ml}$ of aqua regia and $1 \mathrm{ml}$ of perchloric acid added to 100 $\mathrm{ml}$ of water samples in a culture test tube, then incubated at $80^{\circ} \mathrm{C}$ in a water bath, after total digestion and subsequent cooling, the solution was diluted to $50 \mathrm{ml}$ and analyzed for heavy metals. For the determination of 'total' heavy metal concentrations, water samples were digested in aqua regia $(1: 3 \mathrm{HNO} / \mathrm{HCl})$ and $\mathrm{HCLO} 4$ according to the international standard [8].

Soil Sampling and Analysis: Greenhouse soil samples were taken at a depth of $0-30 \mathrm{~cm}$ and these were airdried, sieved $(<2 \mathrm{~mm})$ and stored in polyethylene bags sealed awaiting analysis.

Soil samples were analyzed for nitrate as NO3-N by the Cadmium Reduction Flow Injection Method, [6]. For the determination of 'total' heavy metal concentrations, soil samples were digested in aqua regia (1:3 $\mathrm{HNO} 3 / \mathrm{HCl}$ ) and $\mathrm{HCLO} 4$ according to the international standard [8]. Sequental extraction method [9] was applied to soil samples to identify metal fractions. The heavy metal sequential extraction procedure had the following steps:

- F1. $1 \mathrm{M} \mathrm{MgCl} 2(1: 8 \mathrm{w} / \mathrm{v}, \mathrm{pH}$ 7) for $1 \mathrm{~h}$ at room temperature; metals in soil solution and in exchangeable forms.

- F2. $1 \mathrm{M} \mathrm{NaOAc}(1: 8 \mathrm{w} / \mathrm{v}, \mathrm{pH} 5)$ for $5 \mathrm{~h}$ at room temperature; metals mainly in the carbonate fraction.

- F3. $0,04 \mathrm{M} \mathrm{NH} 2 \mathrm{OH} / \mathrm{HCl}$ in $25 \%(\mathrm{v} / \mathrm{v}) \mathrm{HOAc}(1: 20 \mathrm{w} / \mathrm{v})$ for $6 \mathrm{~h}$ at $96^{\circ} \mathrm{C}$; metals associated with $\mathrm{Fe}$ and Mn oxides.

- $\quad \mathrm{F} 4.3 \mathrm{ml} 0,02 \mathrm{M} \mathrm{HNO} 3+5 \mathrm{ml} 30 \% \mathrm{H} 2 \mathrm{O} 2(\mathrm{pH} 2)$ for $3 \mathrm{~h}$ at $85^{\circ} \mathrm{C}$; metals associated with organic matter.

- F5. HNO3-HCl digestion; residual fraction.

$\mathrm{Fe}, \mathrm{Zn}, \mathrm{Mn}, \mathrm{Cu}, \mathrm{Cd}, \mathrm{Ni}, \mathrm{Cr}, \mathrm{Pb}$ and $\mathrm{As}$ concentrations of groundwater and greenhouse soil samples were analyzed using ICP-MS under optimized measurement conditions and values were adjusted for oven dried $(12 \mathrm{~h}$ at $105 \square \mathrm{C}$ ) material.

\subsection{Pollution Evaluations}

Selected environmental pollution indexes for water samples were used for comprehensive and integrated evaluation of heavy metal pollution. In this study several evaluation methods developed for heavy metal pollution were modified for assessment of nitrate pollution in groundwaters. 


\subsection{HPI İndex.}

was developed by assigning a rating or weightage (Wi) for each chosen parameter. In computing the HPI for the present water quality data, the concentration limits i.e. the standard permissible value ( $\mathrm{Si}$ ) and highest desirable value (Ii) for each parameter were taken from the WHO standards.

The HPI is determined by using the expression below [10]:

$$
H P I=\frac{\sum_{i=1}^{n} W i Q i}{\sum_{i=1}^{n} W i}
$$

Where Qi is the sub-index of the ith parameter. Wi is the unit weightage of the ith parameter and $n$ is the number of parameters considered. The sub-index (Qi) is calculated by

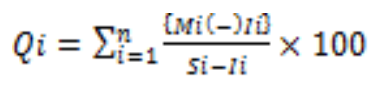

where, Mi, Ii and Si are the monitored value of heavy metal, ideal and standard values of the ith parameter, respectively. The sign (-) indicates numerical differences of the two values, ignoring the algebraic sign.

\subsection{Pollution Evaluation Index (PEI)}

PEI, gives an overall quality of the water with respect to heavy metals, and is computed as:

$$
P E I=\sum_{i=1}^{n} \frac{H_{c}}{H_{\operatorname{mac}}}
$$

Where, Hc and Hmac are the monitored value and maximum admissible concentration (mac) of its parameter, respectively [11]. In this study, PEI was used for both nitrate and heavy metals pollution.

\subsection{Degree of contamination $(\mathrm{Cd})$}

The contamination factor (Cfi) is defined as the ratio of heavy metal concentration in the soil to the background value:

The contamination index $(\mathrm{Cd})$ summarizes the combined effects of several quality parameters considered harmful to household water, and is calculated as follows:

$$
\begin{aligned}
\mathrm{C}_{\mathrm{d}}=\sum_{i=1}^{n} C f i \\
C f i=\frac{\mathrm{CAl}}{C N i}-1
\end{aligned}
$$

where Cfi, CAI and CNI represent contamination factor, analytical value and upper permissible concentration of the ith component, respectively, and $\mathrm{N}$ denotes the normative value. Here, CNI is taken as MAC. The contamination levels were classified by their intensities, ranging from 1 to 3 ( $\mathrm{Cd}<1$ : low, $1<\mathrm{Cd}<3$ $=$ medium, $3<\mathrm{Cd}=$ high) [11].

\subsection{Target hazard quotient (THQ)}

The methodology for estimation of target hazard quotient (THQ) although does not provide a quantitative estimate on the probability of an exposed population experiencing a reverse health effect, but it offers an indication of the risk level due to pollutant exposure. This method was available in US EPA Region III Risk based concentration table and it is described by the following equation [12]:

$$
\mathrm{THQ}=\frac{\mathrm{E}_{\mathrm{Fr}} \times \mathrm{E}_{\mathrm{D}} \times \mathrm{F}_{\mathrm{IR}} \times \mathrm{C}_{\mathrm{m}} \times 10^{-3}}{\mathrm{R}_{\mathrm{fD}} \times \mathrm{B}_{\mathrm{W}} \times \mathrm{A}_{\mathrm{T}}}
$$

Where EFr is exposure frequency (365 days/year); ED is the exposure duration (70 years), equivalent to the average lifetime; FIR is the food ingestion rate $(2000 \mathrm{~g} /$ person/day (FAO, 2005); $\mathrm{Cm}$ is the contaminant concentration in water ( $\mu \mathrm{g} g \_$1); RfD is the oral reference dose of contaminant (US EPA, 1997, 2000); Bw is the average body weight (70 kg), and AT is the averaging exposure time for non-carcinogens (365 days/ year x ED). 


\subsection{Hazard Index (HI)}

For carcinogenic health effects posed by contaminant in drinking water, the Hazard index (HI) was calculated using the following equation [13]. A HI value more than 1 (HI>1) shows a significant risk level. The higher the value, the greater the likelihood of adverse non-carcinogenic health effect.

$$
\mathrm{HI}=\sum_{n=1}^{i} T H Q n \quad(6)
$$

\subsection{Potential Ecological Risk Index (RI)}

Potential ecological risk index (RI), which was developed to scree sediment contamination degree caused by heavy metals was introduced to assess the ecological risk degree of heavy metals in present water, soil and sediments [14]. The value of RI can be calculated by the following formulas:

$$
\begin{gathered}
R I=\sum_{i=1}^{n} E_{r}^{\mathrm{i}} ; \quad E_{r}^{\mathrm{i}}=T_{r}^{\mathrm{i}} \times C_{f}^{i} \\
C_{f}^{i}=\frac{c_{D}^{i}}{c_{g}^{i}} \quad \text { (7) }
\end{gathered}
$$

where RI is the sum of the potential risk of individual heavy metal, Er i is the potential risk of individual heavy metal, $\mathrm{Tr}$ is the toxic-response factor for a given contaminant, $\mathrm{Cfi}$ is the contamination factor, $\mathrm{CD} \mathrm{i}$ is the present concentration of heavy metals, and CB $\mathrm{i}$ is the maximum permissible concentration of contaminant.

Statistical analyses were performed by using SPSS-16 for Windows program.

\section{Result And Discussion}

\subsection{Land Altitude and Groundwater Table in Greenhouse Areas}

Land Altitude and groundwater table in greenhouse regions of Antalya are given in Figure 2. Land altitude of greenhouse regions are varied in a wide range and groundwater table is changed depending on the regions. Finike, Kaş, Kumluca, Manavgat regions have a low altitude, very near to Mediterranean sea and groundwater table of these regions are below the sea level. This means that there is a possibility of seawater intrusion to aquifers in these regions. Land altitude, water table properties, and differences of agricultural practices among the greenhouse regions may be affective on pollution and contamination characteristics of groundwater's.

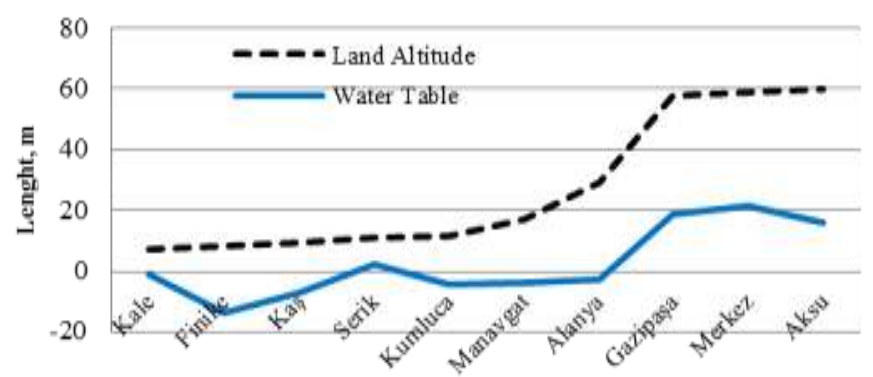

Fig 2. Altitude and Groundwater Table of Greenhouse Regions in the Greenhouse Regions of Antalya, Turkey

\subsection{Groundwater Properties}

Physico-chemical characteristics of groundwaters in the majority of greenhouse areas were within the acceptable limit values and differences in characteristics among the regions were found statistically important (Table I). Groundwater temperatures were detected in acceptable ranges. Groundwaters in greenhouse areas have ranged slightly alkaline and slightly acidic reaction, and generally low electrical conductivity. Although groundwaters in Serik, Kumluca, Kale and Finike regions have generally high electrical conductivity values, in general evaluation, water characteritics with regard to irrigation quality is found acceptable range. Although Finike, Kaş, Kumluca, Manavgat regions have a low altitude and very near to Mediterranean sea, there were not detected a high salinity values in these groundwaters. Dissolved oxygen (DO), biological oxygen demand (BOD), 
chemical oxygen demand (COD) and total dissolved solids (TDS) were detected in acceptable ranges. These values indicate that groundwaters in greenhouse regions were not polluted by organic solids, and physiochemically may be accepted clean.

Nitrate contents of groundwaters in Centre, Serik, Kumluca and Finike regions have ranged in acceptable levels. However total NO3- values of groundwaters in other regions were generally exceeded permissible safe limits [16] for drinking waters. High concentration of NO3- in these areas is of course may be due to highly intensive agricultural practices for all season. Mineralized nitrogen fertilizers such as ammonium nitrate and urea applied in greenhouses appeared to be the dominant source of NO3- in the groundwaters, with contributions from native soil organic matter, and organic amendments. Leaching of nitrates into shallow groundwater under greenhouse agriculture may be accepted high because of the relatively large irrigation density and fast chemical and microbial degradation and nitrification processes under the greenhouse conditions.

Nitrate $\mathrm{Cd}$ values of groundwaters were generally found in low levels. However, Cd was found in medium contamination levels in Manavgat and Alanya regions (Fig 3). Nitrate pollution evaluation values (PEIN) of groundwaters are indicated in Fig 4. PEIN values of groundwaters were below the referenced limit value (40). THQ values in the groundwaters of Aksu, Manavgat, Alanya, Gazipaşa and Kaş regions were exceeded limit value 1 (Fig 5). These evaluations show that due to high contents of NO3- there are a possible health risks for the consumptions of groundwaters as drinking water in a moderate and long-term in the greenhouse regions.

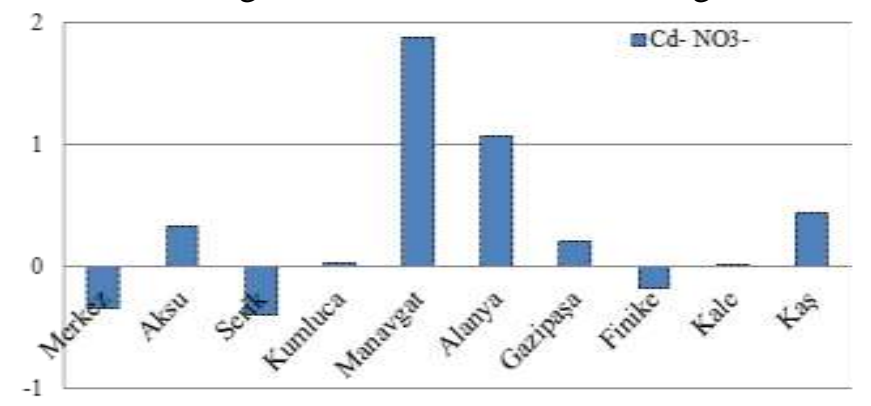

Fig 3. Contamination Degree Values of $\mathrm{NO}_{3}{ }^{-}$in the Groundwaters.

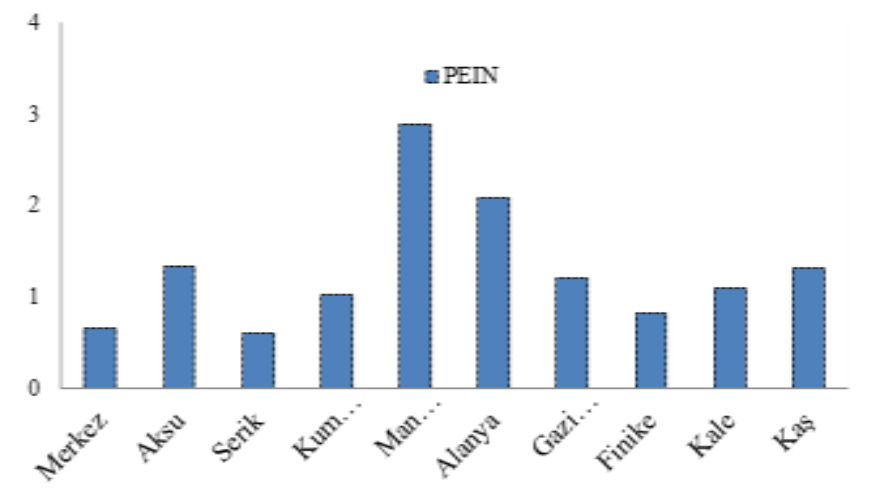

Fig 4. Pollution Evaluation Index Values of $\mathrm{NO}_{3}^{-}$in the Groundwaters. 


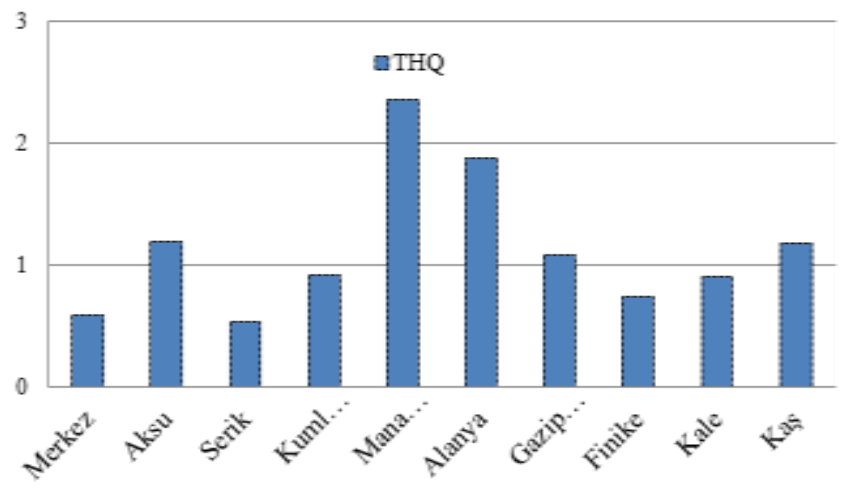

Fig 5. Target Hazard Quotient Values of NO3- in the Groundwaters.

TABLE I. Some Physico-Chemical Parameters of Groundwaters in the Greenhouse Regions of Antalya, Turkey.

\begin{tabular}{|c|c|c|c|c|c|c|c|c|c|}
\hline Sites & $\begin{array}{c}\text { Temperature, } \\
{ }^{\circ} \mathrm{C}\end{array}$ & $\begin{array}{c}\mathrm{EC} \\
\mu \mathrm{S} \mathrm{cm}^{-1}\end{array}$ & $\mathrm{pH}$ & $\begin{array}{l}\text { Alkalinity } \\
\text { mg L-1 }\end{array}$ & $\begin{array}{l}\mathrm{NO}_{3} \\
\mathrm{mg} \mathrm{L}^{-1}\end{array}$ & $\begin{array}{c}\text { DO } \\
\text { mg L-1 }\end{array}$ & $\begin{array}{l}\text { BOD } \\
\mathrm{mg} \mathrm{L}^{-1}\end{array}$ & $\begin{array}{l}\mathrm{COD} \\
\mathrm{mg} \mathrm{L}^{-1}\end{array}$ & $\begin{array}{c}\text { TDS } \\
\mathrm{mg} \mathrm{L}^{-1}\end{array}$ \\
\hline 1. Centre & 18,0 & 624,4 & 7,36 & 120 & 32,6 & 5,54 & 5,25 & 5,85 & 775 \\
\hline 2. Aksu & 18,4 & 680,7 & 7,34 & 180 & 66,6 & 5,57 & 6,35 & 6,45 & 815 \\
\hline 3. Serik & 18,5 & 910,9 & 7,48 & 210 & 29,69 & 5,34 & 3,25 & 3,85 & 850 \\
\hline 4. Kumluca & 19,4 & 823,5 & 7,49 & 205 & 51,1 & 5,45 & 8,65 & 9,05 & 675 \\
\hline 5. Manavgat & 18,0 & 300,7 & 8,07 & 330 & 144,2 & 5,70 & 2,28 & 3,35 & 215 \\
\hline 6. Alanya & 19,0 & 602,8 & 7,33 & 85 & 103,8 & 5,92 & 1,15 & 1,25 & 410 \\
\hline 7. Gazipașa & 18,6 & 728,5 & 7,02 & 75 & 60,2 & 5,45 & 1,25 & 1,25 & 480 \\
\hline 8. Finike & 17,8 & 1307,4 & 7,51 & 190 & 41,3 & 5,33 & 5,30 & 5,60 & 1050 \\
\hline 9. Kale & 19,0 & 916,8 & 7,05 & 80 & 50,4 & 5,26 & 9,25 & 9,55 & 890 \\
\hline 10. Kaș & 18,2 & 776,1 & 7,25 & 95 & 71,70 & 5,34 & 8,25 & 8,35 & 990 \\
\hline Significancy & $5,203 * *$ & $2,784 * *$ & $3,243 * *$ & 6,225 ** & $5,02 * *$ & 9,131 ** & $4,771 * *$ & $5,654 * *$ & $14,254 * *$ \\
\hline Limit values [15] & 25 & $<750$; & $6.5-8.5$ & 600 & 50 & $5<$ & $<10$ & $<10$ & $<1500$ \\
\hline
\end{tabular}

In Table II Pearson's correlation cofficients showing relationship between water physico-chemical parameters and groundwater geographic parameters were presented. Water EC and nitrate contents were positively correlated with water table. However, nitrate and EC values were negatively correlated with land altitude. This means that at higher groundwater levels, nitrate contents are increasing and the amount of nitrate passing through the groundwater decreases as the depth of soil profile and land altitude is increased. This indicates that land elevation and groundwater level are important parameters in contamination of groundwater.

Table 2. Pearson's Correlation Cofficients Showing Relationship Between Water Physico-Chemical Parameters and Groundwater Geographic Parameters.

\begin{tabular}{l|ccccc}
\hline & $\begin{array}{c}\text { Water } \\
\text { table }\end{array}$ & $\begin{array}{c}\text { Land } \\
\text { Altitude }\end{array}$ & $\mathrm{pH}$ & $\mathrm{EC}$ & Nitrate \\
\hline Water table & 1,000 & & & & \\
Land Altitude & $0,763 * *$ & 1,000 & & & \\
$\mathrm{pH}$ & $-0,074$ & $-0,165$ & 1,000 & & \\
$\mathrm{EC}$ & $0,269^{* *}$ & $-0,297 * *$ & 0,045 & 1,000 & \\
Nitrate & $0,238^{* *}$ & $-0,261 * *$ & $-0,144$ & $0,406^{* *}$ & 1,000 \\
\hline
\end{tabular}

\subsection{Soil and Groundwater Heavy Metal Characteristics}

Soil total metal concentrations were significantly varied in sampling sites (Table III ). All average total metal concentrations except $\mathrm{Ni}$ were belove the limits of European Union (86/278/EEC) [16] directive to agricultural soils with $\mathrm{pH}>7$. Ni concentrations in most of soil samples were higher than limit values. Based on 
the greenhouse soil metal concentrations, it can be assumed that no contamination possibility risk with the exception of Ni will recorded.

Total As and Fe contents of all ground waters with the exception of Kale site were above the permissible pollution limits (Table III). Zinc content of groundwaters in Serik and Kaş sites were exceeded a bit more the permissible limits. Cupper and $\mathrm{Pb}$ were detected above the referenced limits in groundwaters in Kaş and Aksu sites, All other metal concentrations in ground waters of greenhouse areas were below the referenced toxicity limits for drinking waters.

Table III. Nitrate and Total Heavy Metal Concentrations of Greenhouse Soils (mg kg-1 Dry Matter).

\begin{tabular}{|c|c|c|c|c|c|c|c|c|c|c|}
\hline WiteW & $\mathrm{NO}_{3}^{-}$ & $\mathrm{Fe}$ & $\mathrm{Zn}$ & $\mathrm{Mn}$ & $\mathrm{Cu}$ & $\mathrm{Cd}$ & $\mathrm{Pb}$ & $\mathrm{Ni}$ & $\mathrm{Cr}$ & As \\
\hline 1. Centre & 65 & 13197 & 125,03 & 420,25 & 38,24 & 0,535 & 23,30 & 99,505 & 41,42 & 12,51 \\
\hline 2. Aksu & 135 & 11482 & 76,40 & 345,10 & 34,32 & 0,434 & 17,02 & 72,703 & 39,70 & 21,57 \\
\hline 3. Serik & 74 & 15357 & 83,32 & 456,40 & 37,64 & 0,473 & 18,02 & 101,664 & 51,71 & 7,78 \\
\hline 4. Kumluca & 112 & 13334 & 93,31 & 511,69 & 53,16 & 0,184 & 24,08 & 112,185 & 33,34 & 4,52 \\
\hline 5. Manavgat & 204 & 15907 & 91,94 & 433,18 & 21,17 & 0,302 & 18,99 & 95,613 & 58,00 & 10,83 \\
\hline 6. Alanya & 189 & 17754 & 72,39 & 301,59 & 66,13 & 0,192 & 21,16 & 36,999 & 41,83 & 5,82 \\
\hline 7. Gazipaşa & 125 & 16555 & 104,21 & 369,68 & 40,67 & 0,214 & 36,47 & 35,841 & 26,98 & 11,32 \\
\hline 8. Finike & 88 & 13893 & 94,39 & 432,69 & 57,00 & 0,176 & 16,71 & 106,285 & 29,57 & 4,08 \\
\hline 9. Kale & 94 & 14190 & 64,14 & 338,02 & 27,12 & 0,329 & 19,68 & 9,079 & 48,87 & 11,24 \\
\hline 10. Kaş & 165 & 12545 & 86,72 & 326,04 & 33,85 & 0,274 & 35,76 & 161,209 & 54,41 & 5,58 \\
\hline Mean & 125 & 13827 & 92,72 & 405,13 & 41,50 & 0,342 & 23,02 & 85,837 & 40,74 & 10,53 \\
\hline Significancy & $8,154 * *$ & $8,071 * *$ & $6,490 * *$ & $5,408 * *$ & $5,717 * *$ & $3,195 * *$ & $5,091 * *$ & $10,163 * *$ & $3,022 * *$ & $5,037 * *$ \\
\hline \multicolumn{2}{|c|}{ Metal Limits [16] } & nls & 300 & nls & 140 & 3 & 300 & 75 & 100 & 20 \\
\hline
\end{tabular}

*: $\mathrm{P}<0,05, * *: \mathrm{P}<0,01$, nls: no limitation set

TABLE IV. Heavy Metal Concentrations of Groundwaters in the Greenhouse Regions of Antalya, Turkey.

\begin{tabular}{|c|c|c|c|c|c|c|c|c|c|}
\hline Sites & $\begin{array}{c}\mathrm{Fe}, \\
\mu \mathrm{g} \mathrm{L}^{-1}\end{array}$ & $\begin{array}{l}\mathrm{Zn}, \\
\mu \mathrm{g} \mathrm{L}^{-1}\end{array}$ & $\begin{array}{l}\mathrm{Mn} \\
\mu \mathrm{g} \mathrm{L}^{-1}\end{array}$ & $\begin{array}{c}\mathrm{Cu} \\
\mu \mathrm{g} \mathrm{L}^{-1}\end{array}$ & $\begin{array}{c}\mathrm{Cd} \\
\mu \mathrm{g} \mathrm{L}^{-1}\end{array}$ & $\begin{array}{c}\mathrm{Pb} \\
\mu \mathrm{g} \mathrm{L}^{-1}\end{array}$ & $\begin{array}{c}\mathrm{Ni}, \\
\mu \mathrm{g} \mathrm{L}^{-1}\end{array}$ & $\begin{array}{c}\mathrm{Cr} \\
\mu \mathrm{g} \mathrm{L}^{-1}\end{array}$ & $\begin{array}{c}\mathrm{As}, \\
\mu \mathrm{g} \mathrm{L}^{-1}\end{array}$ \\
\hline 1. Merkez & 1089 & 112 & 16,49 & 9,59 & 0,284 & 6,35 & 5,57 & 14,94 & 13,17 \\
\hline 2. Aksu & 670 & 68 & 15,69 & 4,05 & 0,087 & 19,13 & 5,19 & 15,68 & 15,74 \\
\hline 3. Serik & 773 & 212 & 9,47 & 4,50 & 0,041 & 3,07 & 4,85 & 20,91 & 16,58 \\
\hline 4. Kumluca & 546 & 80 & 42,76 & 7,79 & 0,082 & 4,35 & 5,49 & 4,65 & 17,20 \\
\hline 5. Manavgat & 403 & 174 & 11,12 & 17,08 & 0,065 & 1,65 & 3,58 & 4,00 & 19,31 \\
\hline 6. Alanya & 780 & 44 & 7,39 & 1,82 & 0,091 & 4,38 & 3,50 & 3,80 & 19,85 \\
\hline 7. Gazipaşa & 541 & 97 & 6,27 & 4,88 & 0,150 & 8,04 & 3,24 & 9,66 & 19,87 \\
\hline 8. Finike & 379 & 103 & 12,61 & 11,11 & 0,434 & 7,09 & 3,05 & 6,71 & 17,94 \\
\hline 9. Kale & 242 & 102 & 24,49 & 5,05 & 0,174 & 6,22 & 4,95 & 13,65 & 17,06 \\
\hline 10. Kaş & 748 & 214 & 17,71 & 63,43 & 0,151 & 4,47 & 9,58 & 16,94 & 17,48 \\
\hline Significancy & $5,483 * *$ & $9,021 * *$ & $2,825 * *$ & $3,464 \mathrm{~ns}$ & $1,667 \mathrm{~ns}$ & $1,081 \mathrm{~ns}$ & $2,644 * *$ & $1,03 \mathrm{~ns}$ & $2,123^{*}$ \\
\hline Limit values [14] & 300 & 200 & 400 & 20 & 3 & 10 & 20 & 50 & 10 \\
\hline
\end{tabular}

*: $\mathrm{P}<0,05, * *: \mathrm{P}<0,01$, ns: no significancy

In Table V Pearson's correlation cofficients showing relationship between soil and groundwater parameters were presented. Groundwater nitrate and $\mathrm{Ni}$ concentrations were positively correlated with soil nitrate and $\mathrm{Ni}$ concentrations. It is thought that high total $\mathrm{Ni}$ concentration of greenhouse soils could be effective on $\mathrm{Ni}$ contamination of groundwaters. 
Table V . Pearson's Correlation Cofficients Showing Relationship between Groundwater and Soil Parameters ${ }^{1}$.

\begin{tabular}{lccccccccccc}
\hline & $\mathrm{W}^{2} \mathrm{NO}_{3}{ }^{-}$ & $\mathrm{WFe}$ & $\mathrm{WZn}$ & $\mathrm{WMn}$ & $\mathrm{WCu}$ & $\mathrm{WCd}$ & $\mathrm{WPb}$ & $\mathrm{WNi}$ & $\mathrm{WCr}$ & $\mathrm{WAs}$ \\
\hline $\mathrm{S}^{3} \mathrm{NO}_{3}^{-}$ & $0,941^{* *}$ & $-0,147$ & 0,005 & $-0,227$ & 0,324 & $-0,461$ & $-0,132$ & 0,022 & $-0,495$ & $0,661^{*}$ \\
$\mathrm{SFe}$ & 0,419 & $-0,080$ & 0,094 & $-0,177^{*}$ & $-0,073$ & $-0,030$ & $-0,066$ & $-0,167^{*}$ & $-0,171^{*}$ & $0,165^{*}$ \\
$\mathrm{SZn}$ & $-0,241$ & $0,486^{* *}$ & 0,106 & $-0,123$ & $-0,014$ & $0,257^{* *}$ & 0,057 & $0,255^{* *}$ & $-0,052$ & $-0,200^{*}$ \\
$\mathrm{SMn}$ & $-0,267$ & 0,045 & 0,060 & 0,066 & $-0,116$ & 0,014 & 0,013 & $-0,034$ & 0,019 & 0,025 \\
$\mathrm{SCu}$ & $-0,180$ & 0,096 & $-0,125$ & 0,075 & $-0,052$ & 0,005 & $-0,017$ & 0,015 & $-0,117$ & 0,028 \\
$\mathrm{SCd}$ & $-0,322$ & $0,177^{*}$ & 0,033 & $-0,142$ & $-0,024$ & $-0,010$ & $-0,060$ & $-0,084$ & $-0,014$ & $-0,126$ \\
$\mathrm{SPb}$ & $-0,013$ & $-0,056$ & 0,055 & $-0,133$ & $-0,044$ & $-0,061$ & 0,093 & $-0,058$ & $-0,054$ & $0,247 * *$ \\
$\mathrm{SNi}$ & $-0,079$ & $0,215^{* *}$ & 0,149 & 0,005 & $0,257^{* *}$ & $-0,009$ & $-0,033$ &,$- 165^{*}$ & 0,052 & $-0,125$ \\
$\mathrm{SCr}$ & 0,419 & $0,180^{*}$ & $0,235^{* *}$ & $-0,110$ & 0,150 & $0,227 * *$ & $-0,013$ & 0,102 & $-0,043$ & $-0,006$ \\
$\mathrm{SAs}$ & 0,049 & $-0,051$ & $-0,155$ & 0,008 & $-0,073$ & $-0,091$ & 0,000 & $-0,155$ & $-0,087$ & $-0,052$ \\
\hline
\end{tabular}

${ }^{1}$ : Sample number is $148 ; \mathrm{W}^{2}$ : Groundwater nitrate and metal concentration; $\mathrm{S}^{3}$ : Soil nitrate and total metal concentration.

In Table VI, Pearson's correlation coefficients between groundwater metal concentration and soil metal fractions and metal mobility factor were presented. According to correlation table, most of metals were correlated soil F1 and F2 fractions that represents soil exchangeable and plant available metals. Also soil metal mobility factor that represents mostly water soluble, exchangeable fractions was correlated with groundwater $\mathrm{Zn}$, $\mathrm{Mn}, \mathrm{Cu}$ and As metals. Only Ni element in groundwater was correlated with F5 fraction that represents Ni in soil residual phases. These data shows us the importance of soil metal fractions and metal mobility on groundwater metal characteristics.

Table VI. Pearson's Correlation Cofficients Showing Relationship between Groundwater Metal Concentrations and Soil Metal Fractions and Metal Mobility Factor 1.

\begin{tabular}{|l|c|c|c|c|c|c|c|c|c|}
\hline \multirow{2}{*}{$\begin{array}{l}\text { Soil metal } \\
\text { fractions }\end{array}$} & \multicolumn{9}{|c|}{ Groundwater metal concentrations } \\
\cline { 2 - 11 } & $\mathrm{Fe}$ & $\mathrm{Zn}$ & $\mathrm{Mn}$ & $\mathrm{Cu}$ & $\mathrm{Cd}$ & $\mathrm{Pb}$ & $\mathrm{Ni}$ & $\mathrm{Cr}$ & $\mathrm{As}$ \\
\hline F1 & $0,119^{2}$ & $-0,195^{*}$ & $-0,163^{* *}$ & $-0,057$ & 0,148 & 0,023 & $0,403^{* *}$ & $-0,063$ & $-0,168^{*}$ \\
\hline F2 & $0,358^{* *}$ & $0,314^{* *}$ & $-0,169^{*}$ & $0,280^{* *}$ & $-0,007$ & 0,060 & $0,310^{* *}$ & $-0,052$ & 0,012 \\
\hline F3 & $-0,023$ & $-0,157$ & $-0,184^{*}$ & $-0,065$ & 0,066 & 0,004 & 0,081 & 0,022 & $-0,010$ \\
\hline F4 & 0,100 & $-0,178^{*}$ & $-0,187^{*}$ & $-0,092$ & 0,015 & $-0,154$ & 0,080 & 0,003 & $-0,088$ \\
\hline F5 & $-0,091$ & 0,039 & 0,094 & $-0,052$ & 0,040 & $-0,093$ & $0,404 * *$ & $-0,038$ & 0,014 \\
\hline MF & 0,135 & $0,264^{* *}$ & $-0,221^{* *}$ & $0,203^{*}$ & $-0,058$ & 0,133 & $-0,002$ & $-0,057$ & $-0,160^{*}$ \\
\hline
\end{tabular}

${ }^{1}$ : Sample number is $148 ;{ }^{2}$ :Every value was correlated between groundwater metal and soil metal; MF: Metal mobility factor

HPI values of groundwaters are shown in Figure 4. All groundwaters except in Aksu site were below the referenced limit value 100. Thus all groundwaters except Aksu regions could be accepted clean level in view of metal concentrations.

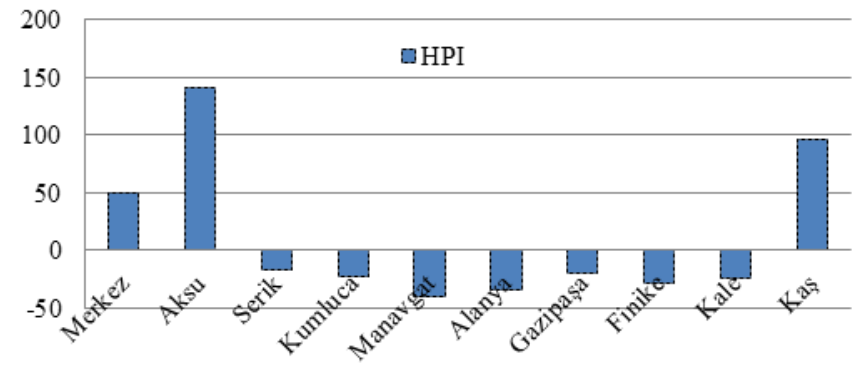

Fig 4. Heavy Metal Pollution Index (HPI) Values of Groundwaters in the Greenhouse Areas.

Heavy metal contamination factor (Cfi) values all metals except Fe were in none to low level (Table VII). Iron Cfi values in groundwaters of Merkez, Aksu, Serik, Alanya and Kaş sites were found between low and moderate levels. Totally, metal contamination degree $(\mathrm{Cd})$ values of groundwaters in the greenhouse sites were 
below the critical value 1 . According to this parameter all of groundwater samples may be considered as less contaminated.

TABLE VII. Heavy Metal Contamination Factor (Cfi) And Metal Contamination Degree (Cd) Values of Groundwaters in the Greenhouse Regions of Antalya, Turkey.

\begin{tabular}{lcccccccccccc}
\hline Sites & $\begin{array}{l}\text { Sample } \\
\text { number }\end{array}$ & Cfi Fe & Cfi Zn & Cfi Mn & Cfi Cu & Cfi Cd & Cfi Pb & Cfi Ni & Cfi Cr & Cfi As & C ${ }_{d}$ \\
\hline 1. Merkez & 29 & 2,629 & $-0,440$ & $-0,835$ & $-0,520$ & $-0,905$ & $-0,365$ & $-0,722$ & $-0,253$ & $-0,342$ & $-0,195$ \\
2. Aksu & 24 & 1,235 & $-0,662$ & $-0,843$ & $-0,798$ & $-0,971$ & 0,913 & $-0,741$ & $-0,216$ & $-0,213$ & $-0,255$ \\
3. Serik & 13 & 1,578 & 0,060 & $-0,905$ & $-0,775$ & $-0,986$ & $-0,693$ & $-0,758$ & 0,045 & $-0,171$ & $-0,289$ \\
4. Kumluca & 28 & 0,820 & $-0,599$ & $-0,572$ & $-0,610$ & $-0,973$ & $-0,565$ & $-0,726$ & $-0,767$ & $-0,140$ & $-0,459$ \\
5. Manavgat & 4 & 0,344 & $-0,130$ & $-0,889$ & $-0,146$ & $-0,978$ & $-0,835$ & $-0,821$ & $-0,800$ & $-0,034$ & $-0,477$ \\
6. Alanya & 9 & 1,599 & $-0,780$ & $-0,926$ & $-0,909$ & $-0,969$ & $-0,562$ & $-0,826$ & $-0,810$ & $-0,008$ & $-0,466$ \\
7. Gazipaşa & 12 & 0,804 & $-0,515$ & $-0,937$ & $-0,756$ & $-0,950$ & $-0,196$ & $-0,838$ & $-0,517$ & $-0,007$ & $-0,435$ \\
8. Finike & 7 & 0,264 & $-0,485$ & $-0,874$ & $-0,444$ & $-0,855$ & $-0,291$ & $-0,848$ & $-0,664$ & $-0,103$ & $-0,478$ \\
9. Kale & 12 & $-0,192$ & $-0,492$ & $-0,755$ & $-0,747$ & $-0,942$ & $-0,378$ & $-0,753$ & $-0,317$ & $-0,147$ & $-0,525$ \\
10. Kaş & 10 & 1,493 & 0,072 & $-0,823$ & 2,172 & $-0,950$ & $-0,553$ & $-0,521$ & $-0,153$ & $-0,126$ & 0,068 \\
\hline Significancy & & $5,483 * *$ & $9,019 * *$ & $2,825 *$ & $3,464 * *$ & $1,666 \mathrm{~ns}$ & $1,081 \mathrm{~ns}$ & $2,645 \mathrm{~ns}$ & $1,030 \mathrm{~ns}$ & $2,123 \mathrm{~ns}$ & $3,488 * *$ \\
\hline
\end{tabular}

$*: \mathrm{P}<0,05, * *: \mathrm{P}<0,01$, ns: no significancy;

HEI values for all of metals in groundwaters of all sites of were below the critical value 40 (Table 8). Thus, all of groundwater samples may be considered as less contaminated and may be acceptable clean.

TABLE VIII. Heavy Metal Evaluation Index Values (Hei)Of Groundwaters In The Greenhouse Regions Of Antalya, Turkey.

\begin{tabular}{lcccccccccc}
\hline Sites & $\begin{array}{c}\text { Sample } \\
\text { number }\end{array}$ & HEI Fe & HEI Zn & HEI Mn & HEI Cu & HEI Cd & HEI Pb & HEI Ni & HEI Cr & HEI As \\
\hline 1. Merkez & 29 & 3,629 & 0,560 & 0,165 & 0,480 & 0,095 & 0,635 & 0,279 & 0,747 & 0,659 \\
2. Aksu & 24 & 2,235 & 0,338 & 0,157 & 0,202 & 0,029 & 1,913 & 0,260 & 0,784 & 0,787 \\
3. Serik & 13 & 2,578 & 1,061 & 0,095 & 0,225 & 0,014 & 0,307 & 0,243 & 1,045 & 0,829 \\
4. Kumluca & 28 & 1,820 & 0,401 & 0,428 & 0,390 & 0,027 & 0,435 & 0,275 & 0,233 & 0,860 \\
5. Manavgat & 4 & 1,344 & 0,871 & 0,111 & 0,854 & 0,022 & 0,165 & 0,180 & 0,200 & 0,966 \\
6. Alanya & 9 & 2,599 & 0,220 & 0,074 & 0,091 & 0,031 & 0,438 & 0,175 & 0,190 & 0,993 \\
7. Gazipaşa & 12 & 1,804 & 0,485 & 0,063 & 0,244 & 0,050 & 0,804 & 0,163 & 0,483 & 0,994 \\
8. Finike & 7 & 1,264 & 0,515 & 0,126 & 0,556 & 0,145 & 0,709 & 0,153 & 0,336 & 0,897 \\
9. Kale & 12 & 0,808 & 0,508 & 0,245 & 0,252 & 0,058 & 0,622 & 0,248 & 0,682 & 0,853 \\
10. Kaş & 10 & 2,493 & 1,072 & 0,177 & 3,171 & 0,050 & 0,447 & 0,479 & 0,847 & 0,874 \\
\hline Significancy & & $5,483 * *$ & $9,022 * *$ & $2,825 *$ & $3,464 * *$ & $1,666 \mathrm{~ns}$ & $1,081 \mathrm{~ns}$ & $2,644 \mathrm{~ns}$ & $1,030 \mathrm{~ns}$ & $2,123 \mathrm{~ns}$ \\
\hline
\end{tabular}

*: $\mathrm{P}<0,05, * *: \mathrm{P}<0,01$, ns: no significancy;

Er and RI values of heavy metals in the groundwaters are shown in Table IX. Er values of individual metals in all sites were below the minimum referenced value 40. RI values that represent the potential ecological risks of all metals in groundwaters of all sites were below the minimum referenced value 150. Er and RI values have not set for Fe element. According to these results, there cannot be expected an ecoloogical risk in a short and medium term. 
TABLE IX. Ecological Risk (Er) And Potential Ecological Risks (Ri) Values Of Heavy Metals In The Groundwaters Of Greenhouse Regions Of Antalya, Turkey.

\begin{tabular}{lccccccccc}
\hline Sites & $\begin{array}{l}\text { Sample } \\
\text { number }\end{array}$ & Er Zn & Er Cu & ErCd & Er Pb & Er Ni & Er Cr & ErAs \\
\hline 1. Merkez & 29 & 0,56 & 2,40 & 2,84 & 3,18 & 1,39 & 1,49 & 6,58 & 18,44 \\
2. Aksu & 24 & 0,40 & 1,10 & 0,58 & 14,13 & 1,49 & 2,22 & 7,87 & 22,52 \\
3. Serik & 13 & 1,06 & 1,13 & 0,41 & 1,54 & 1,21 & 2,09 & 8,29 & 15,72 \\
4. Kumluca & 28 & 0,40 & 1,95 & 0,82 & 2,18 & 1,37 & 0,47 & 8,60 & 15,78 \\
5. Manavgat & 4 & 0,87 & 4,27 & 0,65 & 0,82 & 0,90 & 0,40 & 9,66 & 17,57 \\
6. Alanya & 9 & 0,22 & 0,46 & 0,91 & 2,19 & 0,87 & 0,38 & 9,92 & 14,95 \\
7. Gazipaşa & 12 & 0,48 & 1,22 & 1,50 & 4,02 & 0,81 & 0,97 & 9,94 & 18,94 \\
8. Finike & 7 & 0,51 & 2,78 & 4,34 & 3,54 & 0,76 & 0,67 & 8,97 & 21,58 \\
9. Kale & 12 & 0,51 & 1,26 & 1,74 & 3,11 & 1,24 & 1,37 & 8,53 & 17,75 \\
10. Kaş & 10 & 1,07 & 15,86 & 1,51 & 2,23 & 2,39 & 1,69 & 8,74 & 33,50 \\
\hline \multicolumn{1}{c}{ Mean } & & $0,55^{*}$ & $2,65 * *$ & $1,53 *$ & $3,77 * *$ & $1,29 *$ & $1,19 *$ & $8,30^{* *}$ \\
\hline
\end{tabular}

The heavy metal contamination of groundwaters and the potential health risk were evaluated by THQ and HI (Table X). THQ values of individual heavy metals were all lower than 1 . The cumulative risk of all heavy metals (HI) through the drinking of groundwaters also has not exceeded limit value 1 . This indicated that the daily intake of individual metals through the drinking of groundwaters was unlikely to cause an adverse health risk.

Variation in metal concentrations, HPI, HEI, Er, RI, THQ and HI values of groundwaters, Cfi values of Fe, $\mathrm{Zn}, \mathrm{Mn}$ and $\mathrm{Cu}$ of groundwaters, $\mathrm{C}_{\mathrm{d}}$ values among the sites were found statisticaly significant. Land altitude, water table properties, and differences of agricultural practices among the greenhouse regions may be affected on pollution and contamination characteristics of groundwaters.

TABLE X ThQ and HI values of heavy Metals in the Groundwaters of Greenhouse Regions of aAntalya, Turkey.

\begin{tabular}{lccccccccccc}
\hline Sites & $\begin{array}{c}\text { Sample } \\
\text { number }\end{array}$ & $\mathrm{Fe}$ & $\mathrm{Zn}$ & $\mathrm{Cu}$ & $\mathrm{Cd}$ & $\mathrm{Pb}$ & $\mathrm{Ni}$ & $\mathrm{Cr}$ & $\mathrm{As}$ & $\mathrm{HI}$ \\
\hline 1. Merkez & 29 & 0,0030 & 0,011 & 0,007 & 0,008 & 0,045 & 0,008 & 0,0001 & 0,008 & 0,090 \\
2. Aksu & 24 & 0,0022 & 0,006 & 0,003 & 0,003 & 0,141 & 0,007 & 0,0001 & 0,009 & 0,171 \\
3. Serik & 13 & 0,0023 & 0,020 & 0,003 & 0,001 & 0,022 & 0,007 & 0,0001 & 0,009 & 0,065 \\
4. Kumluca & 28 & 0,0017 & 0,008 & 0,005 & 0,005 & 0,044 & 0,007 & 0,0001 & 0,010 & 0,066 \\
5. Manavgat & 4 & 0,0025 & 0,017 & 0,012 & 0,002 & 0,012 & 0,005 & 0,0001 & 0,011 & 0,062 \\
6. Alanya & 9 & 0,0025 & 0,004 & 0,001 & 0,003 & 0,031 & 0,005 & 0,0001 & 0,011 & 0,058 \\
7. Gazipaşa & 12 & 0,0017 & 0,009 & 0,003 & 0,004 & 0,057 & 0,005 & 0,0001 & 0,011 & 0,092 \\
8. Finike & 7 & 0,0012 & 0,010 & 0,008 & 0,012 & 0,051 & 0,004 & 0,0001 & 0,010 & 0,097 \\
9. Kale & 12 & 0,0008 & 0,010 & 0,004 & 0,005 & 0,044 & 0,007 & 0,0001 & 0,010 & 0,080 \\
10. Kaş & 10 & 0,0030 & 0,021 & 0,045 & 0,011 & 0,068 & 0,011 & 0,0001 & 0,009 & 0,168 \\
\hline Mean & $0,0030^{*}$ & $0,010 * *$ & $0,005^{*}$ & $0,006^{*}$ & $0,036^{*}$ & $0,008 \mathrm{~ns}$ & $0,0001 \mathrm{~ns}$ & $0,008 \mathrm{~ns}$ & $0,076^{*}$ \\
\hline
\end{tabular}

\section{Conclusion}

Results showed us that land altitude, water table properties, and differences of agricultural practices among the greenhouse regions may be affective on contamination characteristics of groundwaters.

Physico-chemical characteristics of groundwaters in the majority of greenhouse areas were within the acceptable limit values and differences in characteristics among the regions were found statistically important. High nitrate contents of groundwaters due to agricultural activities all season in greenhouse regions seem the main threats for public health. According to this, control of nitrate pollution in groundwater especially in greenhouse areas requires a holistic approach to climate land, aquifer and land use factors. 
According to metal evaluation parameters, generally, it can be concluded that all ground waters in regional size may be considered less contaminated, and in point of heavy metals and pollutants is in acceptable limits. Results showed us that soil metal fractions and soil metal mobility factor were also affective on groundwater metal contamination.

\section{Acknowledgment}

This research was sponsored by TUBITAK (The Scientific and Technological Council of Turkey). Author would like to thank to TUBITAK for the financial support of the project (TOVAG-111O711).

\section{References}

[1] Suthar, S., P. Bishnoi, S. Singh, P.K. Mutiyar, A.K. Nema et al. 'Nitrate contamination in groundwater of some rural areas of Rajasthan,India', J. Hazard. Mater., 2009, 171: 189-199.

https://doi.org/10.1016/j.jhazmat.2009.05.111

[2] Cruz, J.V., Silva, M.O., Diaz, M.I., Prudencio, M.I. 'Groundwater composition and pollution due to agricultural practices at sete cidades volcano (Azores, Portugal)’, Applied Geochemistry, 2013, 29:162-173.

https://doi.org/10.1016/j.apgeochem.2012.11.009

[3] Heaton, T., Stuart, M., Sapiano, M., Sultana, M. 'An isotope study of the sources of nitrate in Malta's groundwater', J. Hydrology, 2012, 414(415):244-254. https://doi.org/10.1016/j.jhydrol.2011.10.037

[4] Mahvi, A.H., J. Nouri, A.A. Babei, R. Nabizadeh. 'Agricultural activities impact on groundwater nitrate pollution'. Int. J. Environ. Sci. Tech., 2005, 2: 41-47. https://doi.org/10.1007/BF03325856

[5] Khan, I., H. Ullah, M. Imran. 'Nitrate and phosphate pollution in surface and ground water in Western Malaysia', J. Chem. Soc. Pak., 2007, 29: 315-320.

[6] Clesceri, L., Greenberg, A.E., Eaton, A.D. 'Standard Methods for the Examination of Water and Wastewater, 20th edition', American Public Health Association, 1998, Washington, DC.

[7] APHA, 'Standard Methods for the Examination by Water Waste Water', 16th Edn. APHA, 1985, Washington.

[8] ISO 11466 International Standard. 'Soil quality-extraction of trace elements soluble in aqua regia', 1995,03-01.

[9] Tessier, A., Campbell, P.G.C., Bison, M., 1979. Sequental extraction procedure for the speciation of particulate trace metals. Anal. Chem. 51, 844-851.

https://doi.org/10.1021/ac50043a017

[10] Mohan, S.V., Nithila, P., Reddy, S.J. 'Estimation of heavy metal in drinking water and development of heavy metal pollution index. J. Environmental Sci. Health', 1996, 283-289.

[11] Edet, A.E., Offiong, O.E. 'Evaluation of water quality pollution indices for heavy metal contamination monitoring. A study case from Akpabuyo-Odukpani area, Lower Cross River Basin (southeastern Nigeria)', Geojournal, 2002, 57, 295-304.

https://doi.org/10.1023/B:GEJO.0000007250.92458.de

[12] United States, Environmental Pollution Agency (USEPA), 'Integrated risk information system', 2007, Available from: (http://cfpub.epa.gov/ncea/iris/index.cfm?fuseaction=iris.showSubstanceList).

[13] Xu, X., Zhao, Y., Zhao, X., Wang, Z., Deng, W. 'Sources of heavy metal pollution in agricultural soils of a rapidly industrializing area in the Yangtze delta of China', Ecotoxicology and Environmental Safety, 2014, 108, 161-167. https://doi.org/10.1016/j.ecoenv.2014.07.001 
[14] Hakanson, L. 'An ecological risk index for aquatic pollution control: A sedimentological approach', Water Research, 1980, 14: 975-1001.

https://doi.org/10.1016/0043-1354(80)90143-8

[15] C.E.C. (Council of the European Communities) 1986. Directive of 12 June 1986 on the protection of the environment, and in particular of the soil, when SS is used in agriculture (86/278/CEE). Official Journal of the European Communities, L181, 6-12.

[16] WHO ‘Guidelines for Drinking-Water Quality', Vol. 1, 2000-recommendations, 3rd ed. Geneva: World Health Organization, 2006. 